\title{
Surgical or Non-Surgical Periodontal Treatment: Factors Affecting Patient Decision Making
}

Amit M. Patel, * Philip S. Richards, ${ }^{\dagger}$ Hom-Lay Wang, ${ }^{\dagger}$ and Marita R. Inglehart ${ }^{\dagger}$

Background: This study explored which factors affected patients' decisions to pursue either surgical or non-surgical periodontal treatment.

Methods: Data were collected from 74 patients at a regularly scheduled periodontal appointment, at which each patient was told that periodontal treatment was needed, and 2 weeks following the actual treatment. The surveys assessed the patients' decisions and potential determinants of these decisions. The dental anxiety scale-revised, the state-trait anxiety inventory, and the lowa dental control index were used to measure psychosocial factors.

Results: Patients who decided to have surgery did not differ from patients who decided against surgery in sociodemographic variables such as gender, age, education, and socioeconomic status, nor in their desire for control over the treatment decision. However, they had less dental fear and less general anxiety than the non-surgery patients. Although the two patient groups did not differ in their responses concerning how well the dentists had informed them about the procedure, they differed in the degree of trust and rapport with their dentists.

Conclusions: The less dentally fearful and anxious patients were in general and the more they trusted their provider and felt they had good rapport, the more likely they were to accept surgical periodontal treatment. These results stress the importance of good patient-provider communication. J Periodontol 2006; 77:678-683.

\section{KEY WORDS}

Communication; decision making; dental anxiety; surgery; treatment.

\footnotetext{
* School of Dentistry, University of Michigan, Ann Arbor, MI.

$\dagger$ Department of Periodontics and Oral Medicine, School of Dentistry, University of Michigan.
}

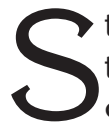
tructural factors that shape future dental health care services, ${ }^{1}$ challenges that dentistry faces currently, 2,3 and recommendations for future dental education ${ }^{4,5}$ point to the significance of providing truly patientcentered care. One important aspect of patient-centered care is the constructive communication between a dentist and a patient during the treatment decisionmaking process. This study explored the factors that affected patients' decisions to pursue surgical versus non-surgical periodontal treatment, and the role that the communication between periodontists and their patients play in these decisions.

Many well-designed clinical studies established the effectiveness of periodontal therapy. ${ }^{6,7}$ Most of these studies focused on dental-treatment outcomes such as the efficacy of the methods, gains in periodontal attachment levels, and the relationship between periodontal probing depths and periodontal attachment when considering whether periodontal disease should be treated non-surgically or surgically. However, even if clinicians and researchers have a clear sense of the efficacy of various treatment approaches and can make definitive treatment recommendations, they still need their patients' consent to actually perform a specific treatment. Therefore, it is of great importance to understand which psychosocial factors shape patient decision making.

doi: 10.1902/jop.2006.050206 
Research showed that certain sociodemographic factors, such as gender, age, and educational background, affect patients' responses to dental treatment. For example, it was found that women tend to report more dental fear than men ${ }^{8-10}$ and that younger patients reported higher levels of dental fear than older patients ${ }^{8,10}$ and were less likely to notice symptoms than older patients. ${ }^{11}$ In addition, patients with higher incomes and education levels reported less fear than patients with lower incomes and lower education levels. ${ }^{9,10}$ Education level might also be correlated with a patient's knowledge about dentistry. Research showed that those patients who lacked knowledge of the dental field preferred a more passive role in the decision-making process. ${ }^{12}$ Given these findings, it may be worthwhile to explore whether these demographic factors would affect periodontal patient decision making.

In addition to considering patient background factors, it may also be of interest to understand the role of dental fear and general anxiety for patients' treatment decision making. Higher levels of general anxiety and dental fear ${ }^{13}$ may affect patients' responses to different treatment options and may even prevent patients from seeking dental treatment. In fact, $\sim 15 \%$ of the world's adult population experience partial avoidance of dental care (going for treatment only when symptoms appear) and another $6 \%$ show total avoidance due to dental fear. ${ }^{13}$ In the context of periodontal decision making, it may be worthwhile to explore whether more generally anxious patients and patients with higher dental fear may be less likely to accept periodontal surgery treatment than patients with less anxiety and fear.

Closely related to dental fear is the degree to which a patient desires to have control in a clinical situation. ${ }^{14}$ Having a sense of control can decrease a patient's level of stress in a dental situation. ${ }^{15,16}$ In addition, negative experiences with dental treatment contributed to patients' lack of trust in their dentists and led consequently to a desire to take a more active role in the decision-making process. ${ }^{12}$ Therefore, it might be worthwhile to explore whether the degree to which a patient desires to have control is related to the degree to which they would like to be involved in the decision-making process.

In addition to patient factors, the actual cost of the treatment ${ }^{17}$ might also affect the patient decisionmaking process. Prior research indicated that having dental treatment paid by a third-party payer (i.e., insurance company) had an effect on the patient decision-making process. ${ }^{17}$ In addition, patients may not only consider monetary costs, but they may also take other costs into consideration, such as the amount of work missed due to the treatment. ${ }^{18}$ Patients' perceptions of costs and benefits may thus affect the decisionmaking process as well. Concretely, it could be pre- dicted that the higher the financial costs, the more time involved in recovery, and the more pain that is expected to result, the less likely a patient will be to choose a certain periodontal treatment.

Finally, the patient-provider relationship ${ }^{12}$ may also influence a patient's decision making. Research showed the connection between the level of trust in a dentist and the patient's degree of passivity in the decision-making process. ${ }^{12}$ Additionally, a patient's lack of knowledge about dental care appeared to be closely related to the trust a patient placed in the dentist's professional status. ${ }^{12}$ Therefore, it seems important to understand how the flow of information from the provider to the patient and the quality of the patient-provider relationship affects the patient's decision to pursue surgical versus non-surgical periodontal treatment.

\section{MATERIALS AND METHODS}

This study was approved by the institutional review board for the health sciences at the University of Michigan.

\section{Respondents}

Data were collected from 74 adult dental patients (32 males and 42 females; average age: 52.65 years; SD: 13.08 years; range: 27 to 83 years) at a regularly scheduled periodontal appointment at a graduate periodontics clinic in a dental school setting between June 24 and August 10, 2004. Some patients had been referred by their private general dentists, by a dentist/graduate student in another graduate clinic (such as the graduate prosthodontics clinic or the patient admitting emergency services clinic), or by junior or senior undergraduate dental students to the graduate periodontics clinic for consults. Some patients had received treatment in the graduate periodontics clinic before. All patients were recruited to participate in this study on the day when the graduate student provider told them that surgical periodontal treatment was recommended. In addition, these patients were also approached 2 weeks after the actual treatment had been conducted. Fifty-five patients (22 males and 33 females; average age: 54.09 years; SD: 12.82 years; range: 29 to 83 years) responded to the follow-up survey. Data were also collected from providers who treated 59 of these patients.

Patients were only included in this study if their provider had recommended surgery. However, the originally recommended type of surgery had not been recorded. Data concerning the actually performed treatment were collected from the 59 providers who responded to the provider survey. They reported that 19 patients had non-surgical scaling and root planing treatment; 12 patients had extractions; eight patients had implants; six patients each had flap surgery, 
connective tissue grafts, and socket preservation therapy; and four patients each had frenectomy surgery and osseous surgery. Some patients had more than one of these surgeries.

\section{Procedure}

When the patients arrived for a regularly scheduled periodontal appointment at the periodontics graduate clinic at the School of Dentistry, University of Michigan, they were informed about their need to have periodontal treatment, and they were asked to volunteer to participate in this study. If the patients agreed to participate, they were asked to give written consent to respond to a baseline and follow-up survey and have their provider share information about their treatment with the researcher. The patients responded to the baseline survey immediately after their providers informed them that they needed surgical periodontal treatment. Of the 74 patients who responded to this baseline survey, 55 patients had their treatment conducted at the graduate periodontics clinic. The providers were periodontal graduate students who had been in their graduate program for at least 1 complete year of training. After the actual periodontal treatment had been performed, the providers of these 55 patients were asked to volunteer to respond to a provider questionnaire concerning each patient's treatment. Two weeks after the treatment was conducted, the patients responded to a followup survey either at their visit to the periodontics graduate clinic or via a phone call. The purpose of this follow-up questionnaire was to assess the patients' evaluations of the treatment after it had been completed.

\section{Materials}

The data were collected in self-administered questionnaires. If the patients did not have a 2 -week follow-up appointment, the follow-up patient survey was administered in phone interviews. The baseline survey contained demographic questions and single item measures and scales assessing psychosocial variables. Dental fear was assessed with the dental anxiety scale-revised (DAS-R). ${ }^{19}$ This scale is a revised version of the original DAS ${ }^{20}$ that had been developed to assess the tendency to appraise dental treatment situations as dangerous and threatening. Ronis et al. ${ }^{19}$ revised and validated a gender-neutral version of the DAS, the DAS-R. Both scales consist of four multiple-choice questions, each with five alternative responses ranging in value from 1 being the most calm choice to 5 being the most anxious choice. DAS scores accordingly can range from 4 to 20. The DAS-R has been shown to be reliable (Cronbach $\alpha=$ 0.81 ) and valid (convergent validity $=0.61) .{ }^{21}$ In reviewing the most commonly used dental-anxiety measures, the DAS-R best suited the design in this study, which focused on the dental anxiety in a treatment situation.

General trait anxiety was measured with the statetrait anxiety inventory (STAI). ${ }^{22}$ In reviewing statetrait anxiety measures used in dental situations, the STAI of Spielberger ${ }^{22}$ has been used almost unanimously. In the current study, the trait anxiety scale that measures a patient's tendency to become anxious was used. This scale is reliable (test-retest reliability $=0.73$ ) and internally consistent (internal consistency $r=0.93) .{ }^{22}$ The trait anxiety scale used in this research consists of 20 items that determine whether the patient is a generally anxious person. Answers are given on four-point answering scales with 1 indicating "almost never," 2 being "sometimes," 3 indicating "often," and 4 being "almost always." Therefore, scores range from 20 to 80 , with a higher score indicating a higher level of trait anxiety.

To assess whether the patients wanted control in the treatment situation, their desire for control was measured with the lowa dental control index (IDCI). ${ }^{14}$ This index was developed to specifically measure the desire of control in a dental setting. The index is based on the sum of the answers to two questions (reliability: Cronbach $\alpha=0.63$ ). The responses to the two items are given on five-point answer scales ranging from 1 being "no control" to 5 indicating "total control." The two items have face validity.

\section{Statistical Methods}

The data were analyzed with statistical software. ${ }^{\ddagger}$ The responses of the patients who decided to be nonsurgically treated (with scaling and root planing) were compared to the responses of the patients who chose surgical periodontal treatment. If the dependent variables were categorical (such as gender), chi square analyses were performed. If the dependent variables were measured on an interval scale, $\mathrm{t}$ - tests for independent samples were conducted.

\section{RESULTS}

Fifty-one of the 74 patients decided to have periodontal surgery, 22 chose to have non-surgical treatment, and one patient did not have any treatment at all. Patients who decided to have surgery did not differ from the patients who made the decision to be treated nonsurgically in background variables such as gender, age, educational background, and socioeconomic status (Table 1). However, there was a tendency for surgically treated patients to have more years of education and to have a higher monthly income than nonsurgically treated patients.

As listed in Table 2, the surgery patients had significantly less dental fear (five-point scale: 1.95 versus $2.39 ; P=0.026$ ), and less trait anxiety than the

‡ SPSS version 11.5, SPSS, Chicago, IL. 
Table I.

\section{Comparisons of Background \\ Characteristics of Surgically and Non-Surgically Treated Patients}

\begin{tabular}{lccc}
\hline $\begin{array}{l}\text { Background } \\
\text { Characteristics }\end{array}$ & $\begin{array}{c}\text { Surgical } \\
\text { Treatment }\end{array}$ & $\begin{array}{c}\text { Non-Surgical } \\
\text { Treatment }\end{array}$ & $P$ Value \\
\hline Gender & $\begin{array}{c}19 \text { males; } \\
32 \text { females }\end{array}$ & $\begin{array}{c}12 \text { males; } \\
10 \text { females }\end{array}$ & NS \\
Age (years) & 52.16 & 53.77 & NS \\
$\begin{array}{c}\text { Education (years of } \\
\text { schooling received) }\end{array}$ & 14.67 & 13.30 & 0.088 \\
Monthly income* & $4.85^{*}$ & 4.77 & 0.08 \\
\hline
\end{tabular}

NS $=$ not statistically significant.

* Measured with the following categories: $1=<\$ 500 ; 2=\$ 500$ to $<\$ 1,000$;

$3=\$ 1,000$ to $<\$ 1,500 ; 4=\$ 1,500$ to $<\$ 2,000 ;$ and $5=>\$ 2,000$.

Table 2.

Average Dental Fear, General Anxiety, and Desire for Control of Surgically and Non-Surgically Treated Patients

\begin{tabular}{|c|c|c|c|}
\hline & $\begin{array}{c}\text { Surgical } \\
\text { Treatment }\end{array}$ & $\begin{array}{c}\text { Non-Surgical } \\
\text { Treatment }\end{array}$ & $P$ Value \\
\hline Dental fear* & 1.95 & 2.39 & 0.026 \\
\hline Trait anxiety ${ }^{\dagger}$ & 1.58 & 1.77 & 0.09 \\
\hline Desire for control ${ }^{\ddagger}$ & 2.48 & 3.11 & 0.311 \\
\hline
\end{tabular}

* Answers to questions on the DAS- ${ }^{1}$ were given on a five-point scale, with $1=$ "no dental fear" and 5 = "extreme dental fear."

$\dagger$ Answers to questions on the $\mathrm{STAl}^{2}$ were given on a four-point scale, with $1=$ "no trait anxiety" and 4 = "extreme trait anxiety."

\# Answers to the questions of the $\mathrm{IDCl}^{3}$ were measured on a five-point scale, with $1=$ "no control desired" and $5=$ "total control desired."

non-surgery patients (four-point scale: 1.58 versus $1.77 ; P=0.09)$. However, the two patient groups did not differ in the degree to which they wanted to have control over the treatment decision.

In addition, although patients in both groups had similar responses to the items concerning treatment cost (Table 3 ) and how much the treatment would interfere with their lives, there was a tendency for the surgery patients to evaluate the effectiveness of their treatment as higher than the non-surgery patients (five-point scale: 4.27 versus 3.82; $P=0.072$ ).

Table 4 provides an overview of the average responses to the three questions concerned with the flow of information from the periodontist to the patient and the five questions concerned with the affective side of the patient-provider relationship. The surgically treated patients did not differ from the non-
Table 3.

\section{Treatment and Cost Considerations of Surgically and Non-Surgically Treated Patients}

\begin{tabular}{c|ccc}
\hline & $\begin{array}{c}\text { Surgical } \\
\text { Treatment }\end{array}$ & $\begin{array}{c}\text { Non-Surgical } \\
\text { Treatment }\end{array}$ & P Value \\
\hline $\begin{array}{c}\text { How much of a } \\
\text { financial burden will } \\
\text { the treatment be? }\end{array}$ & 3.06 & 2.64 & NS \\
$\begin{array}{c}\text { How much will the } \\
\text { treatment interfere } \\
\text { with your life? }\end{array}$ & 2.54 & 2.36 & NS \\
$\begin{array}{c}\text { How effective will } \\
\text { the treatment be? }\end{array}$ & 4.27 & 3.82 & 0.072 \\
$\begin{array}{c}\text { At 2-week follow-up: } \\
\text { How much of a } \\
\text { financial burden } \\
\text { was the treatment? }\end{array}$ & 2.84 & 2.44 & NS \\
\hline
\end{tabular}

Responses were given on a five-point rating scale from $1=$ "not at all" to 5 = "very much."

surgically treated patients in their responses concerning the expertise of the periodontist and the amount of received information they had wanted and needed. However, the two groups differed significantly in their perceptions of the affective side of the provider-patient relationship. Compared to non-surgically treated patients, the surgically treated patients liked their provider more (five-point scale: 4.78 versus $4.41 ; P=$ $0.014)$; trusted their providers more (4.63 versus 4.23 ; $P=0.014)$; and were more likely to believe that their dentist was concerned about their oral health (4.84 versus $4.49 ;$ p.041) and was concerned about not inflicting pain (4.74 versus $4.41 ; P=0.041)$, and that their provider listened to them (4.80 versus $4.27 ; P=0.001)$.

In summary, the patients who decided to have periodontal surgery had a lower level of dental fear, less trait anxiety, and a more positive and trusting relationship with their periodontist than the patients who chose not to have periodontal surgery.

\section{DISCUSSION}

All patients included in this study had been informed by their provider that they needed periodontal surgery. However, 23 of the 74 patients did not follow their periodontist's recommendation. A comparison of the responses of the 51 patients who chose to have the periodontal surgery and the 22 patients who chose non-surgical treatment was conducted to gain a better understanding of how these two patient groups differed. The results showed that the two groups did not differ in general background characteristics. Contradictory to the expectation that there might be a 
Table 4.

\section{Evaluations of the Provider-Patient Relationship of Surgically and Non-Surgically Treated Patients}

\begin{tabular}{|c|c|c|c|}
\hline & $\begin{array}{l}\text { Surgical } \\
\text { Treatment }\end{array}$ & $\begin{array}{c}\text { Non-Surgical } \\
\text { Treatment }\end{array}$ & $\begin{array}{c}P \\
\text { Value }\end{array}$ \\
\hline \multicolumn{4}{|l|}{ Informational aspects } \\
\hline My dentist is knowledgeable. & 4.78 & 4.59 & 0.136 \\
\hline My dentist gave me all information I wanted. & 4.78 & 4.55 & 0.127 \\
\hline My dentist gave me all information I needed. & 4.75 & 4.62 & 0.374 \\
\hline \multicolumn{4}{|l|}{ Rapport/trust } \\
\hline I like my dentist. & 4.78 & 4.41 & 0.014 \\
\hline I trust my dentist. & 4.63 & 4.23 & 0.014 \\
\hline My dentist is concerned about my oral health. & 4.84 & 4.59 & 0.041 \\
\hline My dentist listens to me. & 4.80 & 4.27 & 0.001 \\
\hline My dentist is concerned about not inflicting any pain. & 4.74 & 4.41 & 0.041 \\
\hline
\end{tabular}

gender and age difference ${ }^{8-10}$ men and women were equally likely to choose surgery. In addition, patient age was not a significant predictor of the treatment decision. However, there was a tendency for surgically treated patients to have more years of education and a higher monthly income than the non-surgically treated patients. Although the cost of surgical and non-surgical treatment in a dental school setting is reduced compared to the cost for these procedures in a private dental office, there still is a considerable differential between the costs for surgical and non-surgical periodontal treatments. Given this fact and the finding that surgically treated patients had a higher monthly income, it cannot be ruled out that cost was a factor affecting the treatment decision making, and that it might be even more significant in private dental practices. It would be interesting to explore the role of cost in more detail in future research, and especially to explore how cost considerations would be affected by provider-patient communication.

Prior research indicated that patients from lower socioeconomic backgrounds had higher levels of dental fear than patients from higher socioeconomic backgrounds on average..$^{9,10}$ The findings from this study demonstrated that monthly income correlated with trait anxiety, whereas years of education and monthly income were not significantly correlated with dental fear. The higher the patient monthly income was, the less general trait anxiety the patient had $(\mathrm{r}=$ $-0.313 ; P=0.013)$. This finding may indicate that there is a potentially confounding effect of socioeconomic background and general anxiety and their effect on patients' treatment decisions.

However, it was interesting to find that the two patient groups did not differ in the value they placed on financial cost for their treatment decision making. In addition, the two groups did not differ in the degree to which they thought that the treatment would interfere with their lives. Considering the actual recovery process after surgical versus non-surgical treatment, this finding is quite surprising and could be an indicator of a lack of information concerning the immediate consequences of surgical and nonsurgical periodontal treatment. In this context, it is also interesting to consider that the two groups did not differ in their responses concerning the degree to which they perceived to have received information they 1) had wanted and 2) had needed about the treatment options.

The factors that most affected treatment decision making were affective factors, namely the degree of dental fear and general trait anxiety and the level of trust and rapport with the periodontist. The data clearly illustrated that surgically treated patients had less dental fear, lower trait anxiety, and a more positive patient-provider relationship than the nonsurgically treated patients.

\section{CONCLUSIONS}

Although periodontists have the expertise to provide patients with the best treatment plans, they may not be able to actually perform the treatment because patients may not pursue the recommendation made by the periodontist. Therefore, it is crucial for providers to be aware that the quality of the patient-provider relationship is a determining factor in the patient decisionmaking process.

These findings clearly support the recommendations of the Institute of Medicine's report on the future of dental education ${ }^{4}$ to educate future dental health care providers to be more patient centered. Ultimately, positive patient-provider communication will allow dentists to provide optimal treatment for their patients and, thus, increase their patients' periodontal health.

\section{ACKNOWLEDGMENTS}

The authors want to thank Dr. Laurie K. McCauley, chair of the Department of Periodontics and Oral 
Medicine, School of Dentistry, University of Michigan, for her support; Ms. Bonnie J. Loepke, administrator of the graduate periodontics clinic, School of Dentistry, University of Michigan; and the graduate students in the Department of Periodontics and Oral Medicine, School of Dentistry, University of Michigan, for their assistance with the recruitment of study participants and the collection of clinical data. This research was supported by funding from the Department of Periodontics and Oral Medicine, School of Dentistry, University of Michigan, for AMP.

\section{REFERENCES}

1. Valachovic RW, Weaver RG, Sinkford JC, Haden NK. Trends in dentistry and dental education. J Dent Educ 2001;65:539-561.

2. U.S. Department of Health and Human Services. Oral Health in America: A Report of the Surgeon General Executive Summary. Rockville, MD: U.S. Department of Health and Human Services, National Institute of Dental and Craniofacial Research, National Institutes of Health; 2000.

3. Evans CA, Kleinman DV. The Surgeon General's report on America's oral health: Opportunities for the dental profession. J Am Dent Assoc 2000;131:17211728.

4. Field MJ, ed. Dental Education at the Crossroads Challenges and Change. Washington, DC: National Academy Press; 1995:1-20.

5. Tedesco LA. Issues in dental curriculum development and change. J Dent Educ 1995;95:97-148.

6. Ramfjord SP. Long-term assessment of periodontal surgery versus curettage or scaling and root planing. Int J Technol Assess Health Care 1990;6:392-402.

7. Pihlstrom BL, Hargreaves KM, Bouwsma OJ, Myers WR, Goodale MB, Doyle MJ. Pain after periodontal scaling and root planing. J Am Dent Assoc 1999;130: 801-807.

8. Liddell A, Locker D. Gender and age differences in attitudes to dental pain and dental control. Community Dent Oral Epidemiol 1997;25:314-318.

9. Moore R, Birn H, Kirkegaard E, Brodsgaard I, Scheutz $F$. Prevalence and characteristics of dental anxiety in
Danish adults. Community Dent Oral Epidemiol 1993; 21:292-296.

10. Ragnarsson E. Dental fear and anxiety in an adult Icelandic population. Acta Odontol Scand 1998;56: 100-104.

11. Brunsvold MA, Nair P, Oates TW Jr. Chief complaints of patients seeking treatment for periodontitis. J Am Dent Assoc 1999;130:359-364.

12. Chapple H, Shah S, Kay EJ. Exploring dental patients' preferred roles in treatment decision making - A novel approach. Br Dent J 2003;194:321-327.

13. Eli I, Uziel N, Baht R, Kleinhauz M. Antecedents of dental anxiety: Learned responses vs. personality traits. Community Dent Oral Epidemiol 1997;25: 233-237.

14. Burger J. Desire for Control. New York: Plenum Press; 1992:119-138.

15. Logan H, Baron R, Keeley K, Law A, Stein S. Desired and felt control as mediators of stress in a dental setting. Health Psychol 1991;10:352-359.

16. Law A, Logan H, Baron RS. Desire for control, felt control, and stress inoculation training during dental treatment. J Pers Soc Psychol 1994;67:926-936.

17. Simon JF. Retain or extract: The decision process. Quintessence Int 1999;30:851-854.

18. Matthews DC. Decision making in periodontics: A review of outcome measures. J Dent Educ 1994; 58:641-647.

19. Ronis DL, Hansen CH, Antonokos CL. Equivalence of the original and revised dental anxiety scales. J Dent Hyg 1995;69:270-272.

20. Corah NL, Gale EL, Illig SJ. Assessment of a dental anxiety scale. J Am Dent Assoc 1978;97:816-819.

21. Doerr PA, Lang PW, Nyquist LV, Ronis DL. Factors associated with dental anxiety. J Am Dent Assoc 1998;129:1111-1119.

22. Spielberger CD. Manual for the State-Trait Anxiety Inventory (Form Y). Palo Alto, CA: Consulting Psychologists Press; 1983.

Correspondence: Dr. Marita R. Inglehart, Department of Periodontics and Oral Medicine, School of Dentistry, University of Michigan, Ann Arbor, MI 48109-1078. Fax: 734/763-5503; e-mail: mri@umich.edu.

Accepted for publication October 18, 2005. 